\title{
Ethnomedicine and Future Challenges
}

\author{
Suchita Tripathi* \\ Former Faculty, Department of Anthropology and Tribal Development, India
}

Submission: September 18, 2019; Published: September 26, 2019

*Corresponding author: Suchita Tripathi, Former Faculty, Department of Anthropology and Tribal Development, GGV, BIlaspur, CG, 495009, India

\begin{abstract}
Many of traditional oral and indigenous culture of tribal people has been continuously deteriorated due to large scale urban and industrial development in remote forest areas as whole economy, society and cultural legacy of tribal are dependent on their forest land which is favorite abode of tribals. One of them is ethno medical knowledge which is reliant on presence of wild fauna and flora having medicinal value. Ethnomedical knowledge is intellectual property of tribals. Displacement of tribal communities to other places and loss of medicinal plant and animal species very much affect their ethnomedicinal practices. This knowledge is apparent to become extinct in near future because of insecurity of ethnomedicinal plants and animals, limitation of knowledge to only few persons (sacred specialists, diviner, sorcerer) of community, being oral tradition, absence of written form, limitation to cure only small scale diseases and push and pull factor among tribal youths to do government jobs in urban areas. Therefore, it is need of time to preserve this knowledge for future generations Preservation of this traditional knowledge can be done by lessening the exploitation of natural resources, by documentation to make its wider reach, by making tribal youths aware about its benefits and opting this as a carrier option, and most important is by linking this ethnomedicinal knowledge with modern medicine system..
\end{abstract}

Keywords: Ethnomedicine; Tribal People; Exploitation of Natural Resources; Preservation

\section{Introduction}

One of the important characteristics of human life is health which depends on various other socio-cultural and physical aspects. Health is defined as state of physical, mental and social well-being and if any of these states are not well or body is not functioning properly due to some factors then the condition is called as disease and sometimes illness. This is what we know according to scientific facts. But there is found conceptual variations among the villagers, or tribal communities in context of health, disease or illness. Their ideology and viewpoint are somewhat different form scientific approach. They often think that it is God or supernatural powers or magic that controls and causes illness and disease. A medical practitioner cannot solve their problems just by prescribing some medicines. Here is the role of medical anthropologist who studies the causes and treatment of ill health and disease on the basis of native's viewpoint, which may differ among different tribal communities [1]. Anthropologist tries to know what community members feels the reason behind disease, good or bad health, how do they treat such conditions on their own, what medicine or therapy they use to cure a person's physical, mental ailments, what are the misconceptions they have about modern medicine or is there any taboos or fear they have regarding disease or modern medical system. On the basis of the collected data, medical anthropologist prescribes a solution which often fits to whole community member's mindset and culture. In this way, a medical anthropologist works as a social doctor who is different from medical practitioner. Since time immemorial, tribal communities have preserved and maintained their traditional and indigenous knowledge of medicinal plants and animals. Every tribal group has a unique and specific knowledge of ethnomedicinal practices that differs from other tribal groups. Ethnomedicine is a kind of medical system among the tribal communities in which the community members utilize the medicinal plants [2] and animals to cure different diseases.

There are certain similarities and differences in between Ayurveda, Ethnomedicie and Biomedicine. Ayurveda share one thing common with Ethnomedicine is the traditional knowledge and use of herbal plant and some animal products like milk, ghee, honey, cow urine, cow dung etc. The difference lies in the fact that Ayurveda is in written form, is global, and universal and there is neither any use of meat or flesh of animals nor any performance of religio-magical rites for the treatment of diseases. Ayurvedic system prevents and cures the disease by yoga, meditation, philosophy of nature, and by use of herbal drugs. Opposite is the case of ethnomedicine where knowledge is oral not written and is limited to few, local, specialized, tribal medical practitioners called Baiga or shaman.

Ethnomedicine is more ethnic, more magical and less scientific [3]. It is study of healing practices of cultural groups and individual experiences about disease and illness. Ethnomedicine 
allows use of medicinal plant and animal products and magical practices for curing the disease. Biomedicine is the modern medicine system which utilizes the bio-products for treatment of general fever, cold-cough, Gastro-intestinal problems as well as severe chronic diseases with the help of various modern electromagnetic therapies and instruments. It is based on pure scientific knowledge and techniques. Ethno medicine has its limitations that it cannot be effective for deadly diseases like cancer, diabetes, blood pressure. It can only be used for general cold-cough, gastric or liver problems, Joint pain etc. These shortcomings and limitation are major threat to this indigenous knowledge.

\section{Ethnomedicine and Tribal Health}

Since Human's origin on earth, culture, a man-made environment was created by them for the satisfaction of their various primary, derived and integrative bio-psychic needs like hunger, thirst, sex, love, care, affection, shelter along with religion, political and socio-economic needs [4]. Out of this, for healthcare and fitness of body, medicinal knowledge has been developed. Since ancient days, early human ancestors have developed use of nature for survival, healthcare and treatment of diseases. They invented and identified medicinal properties of various plants, animal species and minerals for curative purposes [5,6]. In India, except Allopathy, all other medical systems like Ayurveda, Siddha, Naturopathy, Yunani, Homeopathy along with ethno-medicine mainly depends on herbal drugs for the treatment of diseases. Ayurveda is the oldest medical system which was developed nearly 4500-500 BCE during vedic period and the ayurvedic texts were developed during 1000-800 BCE [7]. In ayurveda, there is mention of thousands of healing herbs, role of God and healer to restore health and demons causing disease. Some researchers found it to be contemporary with origin of Mesopotamian medical system. More than $70 \%$ of Indian population depends on herbal treatment [8]. Over 6000 of 15,000 herbal plant species have been used as herbal drugs or medicine by herbal medical practitioners in India [9]. Generally, Researchers made emphasis on studies of medicinal plants, downgrading the importance of medicinal animals. But recently, this area is also studied by various researches in which mention can be made of [10-14].

Tribal people generally live in forest areas where they become familiar with a variety of plant and animal species which they sustainably use for their food, medicinal purposes [15]. Deforestation and displacement to other places very much effect their culture and economy Roy Burmen [16] and loss of medicinal plant and animal species very much affect their ethnomedicinal practices. like cure of general ailments, fever, gynecological problems etc. [17]. In a study, it is found that in whole world, more than 50,000 plant species are identified to have medicinal value [18].

In one study, in the semiarid northeastern region of Brazil, results suggest that the use of zoo therapeutics in the region is continual, and indigenous knowledge about these curative practices is an integral part of the local culture. Such studies concerning with use of animal-based medicines gives us a pathway to understand cultural interactions between human and environment since past days. A good number of contribution has been made by different scholars and scientists in the field of Indian ethnomedicine in which mention can be made of studies by Brijlal,1993 Maheshwari et.al(1981,1986, 1990, 1996,1999), Naik (2003), Tirkey (2004), Rai \& Nath (2005), Shukla \& Chakravarty (2006), Shrivastava \& Sharma (2010) etc.

With time, due to its limitation to cure only small-scale diseases, and development of other types of medicines, drugs, this knowledge has been continuously vanishing. But still, most of the tribal communities in India has survived this knowledge and are using this knowledge and therapy. In one of the states of Chhattisgarh, many tribal communities are still using ethnomedicinal practices for cure of various diseases. God has gifted Chhattisgarh with abundant biodiversity as 44 percent of the state geographical area is covered by Forests [17]. Tribals of Bastar and other regions of Chhattisgarh use ethnomedicinal practices for treatment of various diseases like cough, cold, fever, skin diseases, stomach problems, healing wounds, etc. by using different parts of various plant species that in turn strengthens traditional healthcare practices in village and also helps in conservation of indigenous knowledge of tribals [19].

Tribals also have ethno-medicinal knowledge (ethnogynaecology) for female health issues and gynaecological problems like menstrual pain, menopause, leucorrhoea, infertility, delivery and abortion etc [20]. Gonds, Kamars, Murias, Marias, Halbas, Saoras, Birhors, Baigas and Binjhwars cure these problems by using flower, stems, roots, leaves, pulp, bark etc. of various plants and herbs. Every tribal group has unique and different technique of using these herbs. Other states with tribal rich population are also practicing this knowledge. Some of the tribes in India like Oraons and Gonds have started to take modern medicine along with ethnomedicine. Many of the tribal populations in the world have started use of CAM therapy for curing the diseases [21]. but still there is lack of documentation of this cultural heritage and few limitations which are needed to be removed by increasing awareness among the people [22,23].

\section{Conclusion}

Ethno medicine is a traditional knowledge which should be preserved as is thought to be vanished in near future. Large scale exploitation of natural resources and dependency on chemical resources in pace of development by human beings open a pathway for future insecurity of natural resources and ultimately loss of human lives. Ethno medicine will be a good option for future generations as it is a technique which involves sustainable use of natural resources which is very important for life on planet earth. In present era, there is going to be scarcity of fresh air, water, food and other natural resources which will affect the survival of plant and animals including human beings on earth. Therefore, 


\section{Global Journal of Archaeology \& Anthropology}

in order to keep our planet green and live, we need to go back to our traditional culture and heritage which gives us lesson of sustainable development with limited and balanced use of natural resources without destroying them so as to make them available for future generations. Ethno-medicine is such knowledge of old people mostly tribal's which utilizes nature in balance for the welfare of society by treating their diseases and ailments with the help of herbs and medicinal animals. It is the cultural heritage of tribal people in which they heal and cure the disease by using some zoo-botanical products and practicing magicoreligious rituals. They have firm belief in their traditional medical system and have fear and misconceptions about the modern medicine system. Therefore, it is need of time to remove all fear and mistaken belief from their mind about modern medicine or allopath, to make tribal youths aware about use and benefits of both their traditional knowledge of medicine and also modern medicine system.

Due to some of its drawbacks like limitation of medicinal knowledge to only few persons of the society, status of local culture not universal, absence of written form, treatment and healing of only small-scale diseases, its future is supposed to be in danger. Therefore, in India, medical pluralism and CAM medicine therapy (co-existence of both conventional medicine along with alternative medicine system). is very much demanding in present scenario. In this way, we can not only preserve our age-old traditional healing system and culture for future generations but will also combat with dreadful diseases and future challenges. Documentation of ethnomedicinal knowledge, adoption of it as carrier option among the tribal youths and promotion of CAM therapy will not only help in preservation of this cultural legacy but also will help in economic upliftment and sustainable development of the society.

\section{References}

1. Helman CG (1984) Culture, Health and Illness, CRC Press, Taylor and Francis group, Florida, USA

2. Souza E, Williamson EM, Hawkins JA (2018) Which Plants Used in Ethnomedicine Are Characterized? Phylogenetic Patterns in Traditional Use Related to Research Effort. Frontiers in plant science 9: 834 .

3. Erickson PI (2007) Ethnomedicine, Waveland Press, p 124.

4. Tripathi S \& Panigrahi N (2017) Changing Sacred status of Village Pond in the context of People-Pond-Spirit Complex: An Empirical Study, The Oriental Anthropologist 17(1): 149-161.

5. Rekka R, Murugesh S, Prabakaran R (2013) Plants used by Malayali Tribes in Ethnogynaecological disorders in Yercaud hill, Southern Eastern Ghats, Salem District, Tamil Nadu. Sci Res Reporter 3: 190-192.

6. Alves RRN, Rosa IL (2012) Animals in Traditional Folk Medicine Implications for Conservation. Berlin Heidelberg: Springer.
7. Magner LN (2005) A history of medicine, Taylor and Francis group, Florida, USA.

8. Vaidya AD, Devasagayam TP (2007) Current status of herbal drugs in India: an overview. Journal of clinical biochemistry and nutrition 41(1): $1-11$

9. Dhamija HK, Parashar B, Singh J (2011) Anti-depression potential of Herbal drugs: An overview. J Chem Pharm Res 3(5): 725-735.

10. Alves RRN, Rosa IL (2005) Why study the use of animal products in traditional medicines? J Ethnobiol Ethnomed 1: 1-5.

11. Alves RRN, Rosa IL, Santana GG (2007) The role of animal-derived remedies as complementary medicine in brazil. Bioscience 57: 949955.

12. Ferreira FS, Brito S, Ribeiro S, Saraiva A, Almeida W, et al. (2009) Animal-based folk remedies sold in public markets in Crato and Juazeiro do Norte, Ceara, Brazil. BMC Complement Altern Med 9: 1-17.

13. Souto W, Mourao JS, Barboza RRD, Alves RRN (2011) Parallels between zootherapeutic practices in Ethnoveterinary and Human Complementary Medicine in NE Brazil. J Ethnopharmacol 134 (3): 753-767.

14. Patel PK (2012) Ethno-gynaecological use of plants from Gujarat India. Bangla. J Plant Taxon 19(1): 93-94.

15. Tripathi S (2017) Birhor and Their Culture: An Ethnographic Account of Particularly Vulnerable Tribal Group of Chhattisgarh, in the book 'JalJangal- Jameen Aur Janjatiyan, Edt. PP Tripathi and PC Joshi, Pratibha Prakashan, Triveni Seva Samiti Sohbatiyabagh, Allahabad (U P), India.

16. Roy Burman BK (1982) Report of Committee on Forest and Tibals in India, TD Division, Ministry of Home Affairs, Govt of India, India.

17. Chakraborty A, Kosariya S, Chakravarty (2015) A Review of Ethnomedicinal Practices for Gynaecological Disorders among the Various Tribes of Chhattisgarh. IOSR Journal of Environmental Science, Toxicology and Food Technology (IOSR-JESTFT) 1(2): 55-62.

18. Sadeghi Z \& Mahmood (2014) A Ethno-gynecological knowledge of medicinal plants used by Baluch tribes, southeast of Baluchistan, Iran. Rev bras farmacogn 24(6): 706-715.

19. Banik A, Nema S (2014) Ethnomedical Practices and Indigenous Household Remedies Used by the Tribals and Rurals of the Bastar Region (Chhattisgarh), The Indian Forester 140(2).

20. Lawal I (2013) Phytotherapy approach for the treatment of Gynaecological disorder among women in Ido Local Goverment Area of Ibadan, Oyo State, Nigeria. J Adv Sci Res 4: 41-44.

21.Gabriel K, Zipporah K (2019) Ethnomedical Survey of the Plants Used by Traditional Healers in Narok County, Kenya, Evidence-Based Complementary and Alternative Medicine.

22. Alves RRN, Souto WMS, Barboza RRD (2010) Primates in traditional folk medicine: a world overview. Mammal Rev 40(2): 155-180.

23. Maheshwari JK, Painuli RM, Dwivdi RP (1997) Notes on Ethnobotany of the Oraon and Korwa Tribes of Madhya Pradesh, In: Contribution to Indian Ethnobotany, by SK Jain (Ed), $3^{\text {rd }}$ Revised Edn, Scientific Publishers, Jodhpur, India, pp 67-82. 
Your next submission with Juniper Publishers will reach you the below assets

- Quality Editorial service

- Swift Peer Review

- Reprints availability

- E-prints Service

- Manuscript Podcast for convenient understanding

- Global attainment for your research

- Manuscript accessibility in different formats ( Pdf, E-pub, Full Text, Audio)

- Unceasing customer service

Track the below URL for one-step submission https://juniperpublishers.com/online-submission.php 